\title{
Reliability Estimation for Highway Bridges
}

\author{
Nafiseh Kiani \\ Dept. of Civil, Architectural, and Environmental Engineering, University of Miami, Coral
}

Gables, FL 33146.

\begin{abstract}
Structural reliability analysis is necessary to predict the uncertainties which may endanger the safety of structures during their lifetime. Structural uncertainties are associated with design, construction and operation stages. In design of structures, different limit states or failure functions are suggested to be considered by design specifications. Load and resistance factors are two essential parameters which have significant impact on evaluating the uncertainties. These load and resistance factors are commonly determined using structural reliability methods. The purpose of this study is to determine the reliability index for a typical highway bridge by considering the maximum moment generated by vehicle live loads on the bridge as a random variable. The limit state function was formulated and reliability index was determined using the First Order Reliability Methods (FORM) method.
\end{abstract}

Keywords: Reliability estimation; Highway bridge; Nonlinear failure function; FORM

\section{Introduction}

Structural reliability is to predict the uncertainties which may endanger the safety of structures during their lifetime. Structural uncertainties are associated with design, construction and operation stages. Reliability methods are employed to estimate the relative probability of failure of the structures. To estimate the reliability, probabilistic concepts including stochastic variables, stochastic processes, and failure mode of the structure need to be investigated. In general, the main purpose of the structural reliability is to recognize the possible failures and formulate failure functions based on relevant parameters [1].

The random variables are commonly defined to quantify the behavior of a structure in response to the failure. The random variables may be considered as load, strength, geometry, and material of a structure. Note that the values of random variables depend on the probability distribution function and they are associated with a probability of occurrence. Random variables are discrete or continuous parameters. A discrete random variable is a function that takes on only a finite number of discrete values, while a continuous random variable is a function which can take on any value within one or several intervals [2]. The probabilistic characteristics of a continuous random variable are described by its cumulative distribution function (CDF). The most important statistical characteristics of a random variable is the mean value, and the standard deviation which shows the measure of the uncertainty [3]. 
In design of structures, different design limit states and load factors are suggested to be considered by design specifications. Load and resistance factors are two essential parameters which have significant impact on evaluating the uncertainties. These load and resistance factors are determined using a comprehensive calibration process based on the reliability methods [4,5]. Therefore, structural models are developed based on the load and resistance factors, then the reliability of structures can be determined by probability of failure functions.

In this study, the reliability analysis was conducted on a typical highway bridge. Nearly $40 \%$ of highway bridges in the US are very old and are reaching their fatigue life [6,7]. Therefore, bridge monitoring efforts have become both much more important and much more expensive due to the sheer number of bridges that require regular inspections [8,9]. As a result, probabilistic methods are necessary to determine the level of safety for various design cases.

\section{Case Study}

A simple span highway bridge with a span length of $120 \mathrm{ft}$. was selected for this study. Since the bridge was subjected to heavy traffic loading, the statistical analysis was focused on vehicle loads. Weight-in-motion (WIM) data was used for calculating the bridge loading. For reliability analysis, 960 vehicle data were considered as an actual applied load. Maximum moments on the bridge produced by the WIM data were calculated for all the considered vehicle data and the statistical parameters are shown in Table 1. The results were compared to the maximum moment produced by the HS20 design truck according to AASHTO bridge design.

\section{Reliability Analysis}

The purpose of this study is to determine the reliability index for a typical highway bridge by considering the maximum moment on the bridge as a random variable. The maximum moment on the bridge is generated by truck live loads, called truck moment $M$ and assumed as a basic random variable in this study. First, the statistical parameters, mean $(\mu)$ and standard deviation $(\sigma)$ for the truck moment $M$ were determined as shown in Table 1 . The histogram plot of the observed traffic flow data is also shown in Fig. 1 which represents the observed number of trucks in each hour.

Table 1. The statistical parameters of truck moments M (kips-ft.)

\begin{tabular}{ll}
\hline Mean & 1002 \\
\hline Standard Deviation & 424.6 \\
\hline Range & 1947 \\
\hline Minimum & 161 \\
\hline Maximum & 2108 \\
\hline Coefficient of Variation & 0.4 \\
\hline
\end{tabular}




\begin{tabular}{lc}
\hline Covariance & 180117 \\
\hline
\end{tabular}

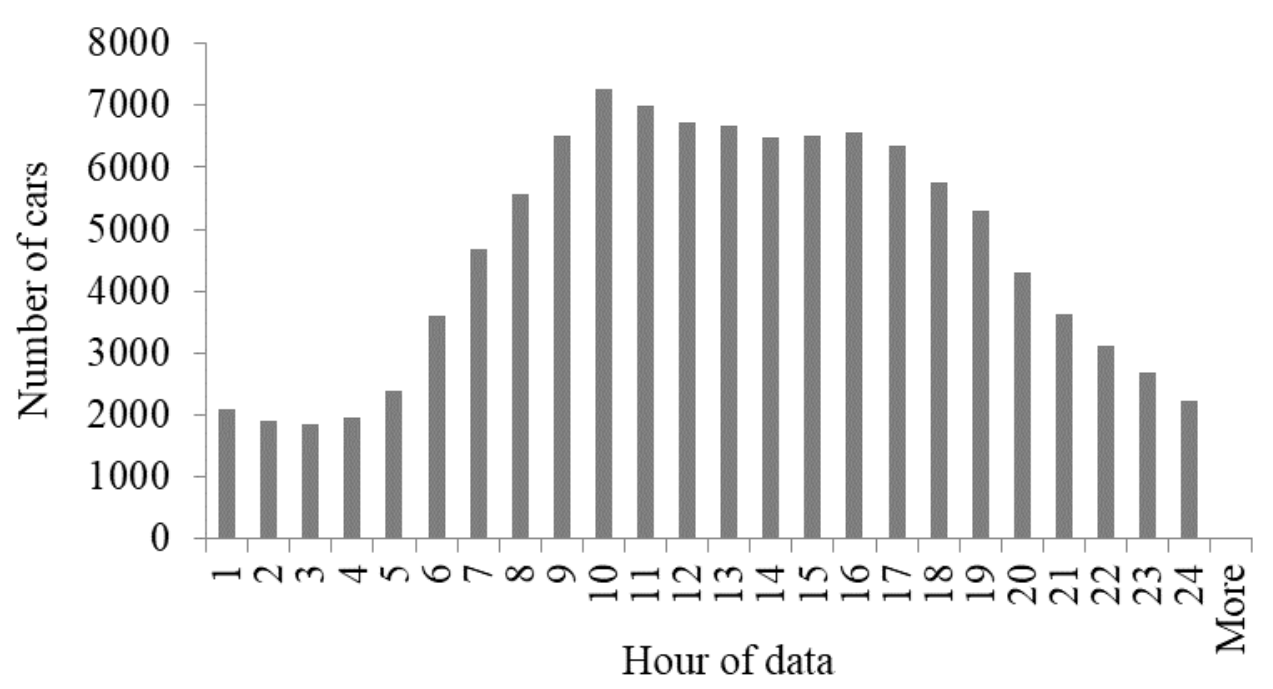

Fig. 1. The histogram plot of the observed traffic flow

The limit state function was formulated based on the criterion that the maximum truck (HS20 design truck) moment on the bridge has to be less than the bridge section capacity according to AASHTO. The limit state or failure function was defined as $f$, where $M$ is the truck moment, $M_{H S 2 O}$ is the moment from HS20 design truck, and $l$ is the span length of the bridge. The moment from the HS20 design truck was obtained from analyzing a simple span bridge according to AASHTO [10]. The failure surface is given by $f\left(M, M_{H S 20}\right)=0$ and the corresponding safety margin was defined as $Z$.

$f\left(M, M_{H S 2 O}\right)=M-M_{H S 20}$

$Z=M-M_{H S 20}=M-181-(389 / 1)+280$

Probability of failure $P_{f}$ is the probability that the truck moment $M$ is less than or equal to the HS20 moment $M_{H S 20}$ or the probability that $Z$ is less or equal to zero. Therefore, the probability of failure is defined as $P_{f}$, where $\Phi$ is the standard normal distribution function, $U$ is a standard normally distributed variable, and $\beta$ is reliability index. The reliability index $\beta$ is described as the smallest distance between the safe domain and the failure surface.

$P_{f}=P(Z \leq 0)=P\left(\mu_{Z}+U \sigma_{Z} \leq 0\right)=P\left(U \leq \frac{\mu_{Z}}{\sigma_{Z}}\right)=\Phi(-\beta)$

When the limit state function is nonlinear, Hasofer and Lind suggested that the failure function is linearized using First Order Reliability Methods (FORM), then reliability index can be estimated 
by level II or III methods [11]. The FORM method is based on the optimization technique, applying an iteration scheme to estimate the reliability index [12].

The cumulative distribution function (CDF) plot of the truck moment is shown in Fig. 2. The shape of the CDF plot is an indication of the type of normal distribution function. Since the resulting CDF plot is close to a straight line, the truck moment $M$ can be considered as a normal random variable. Probability density function (PDF) plot is also shown in Fig. 3.

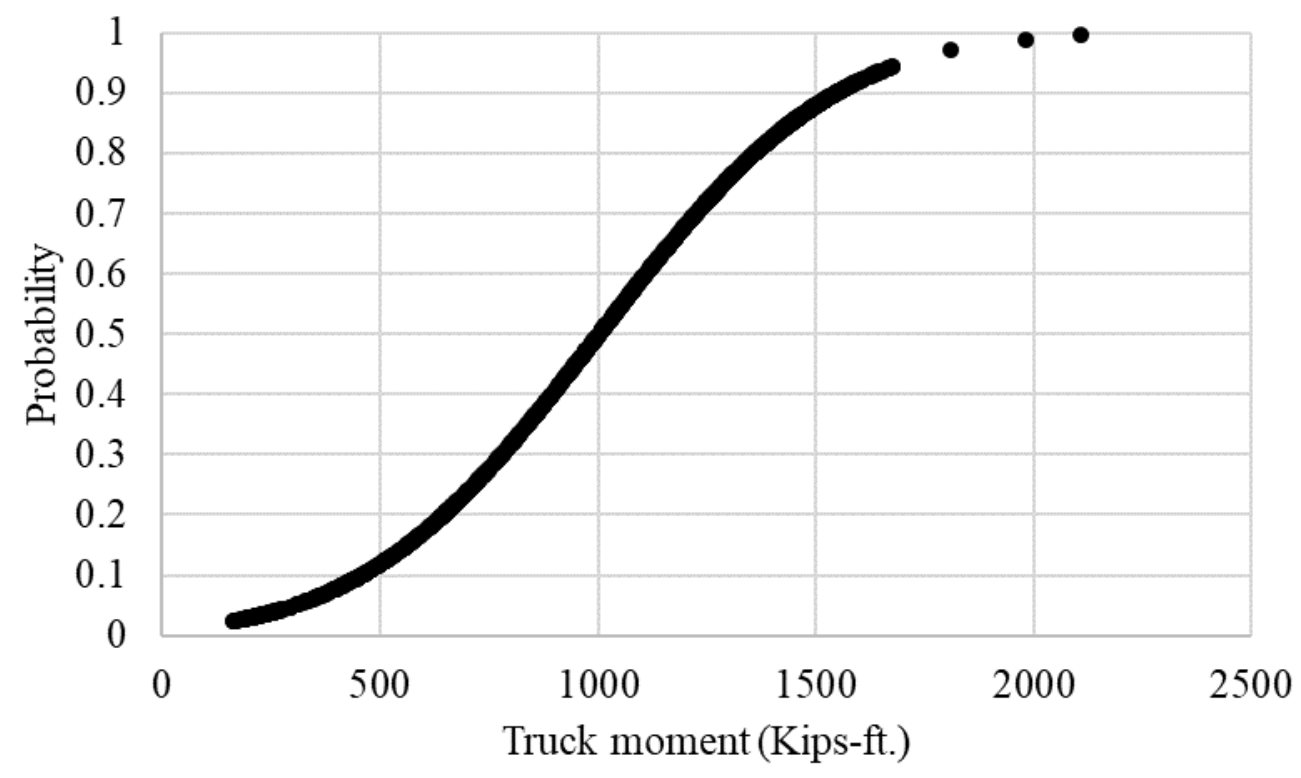

Fig. 2. Cumulative distribution function (CDF) for the truck moment

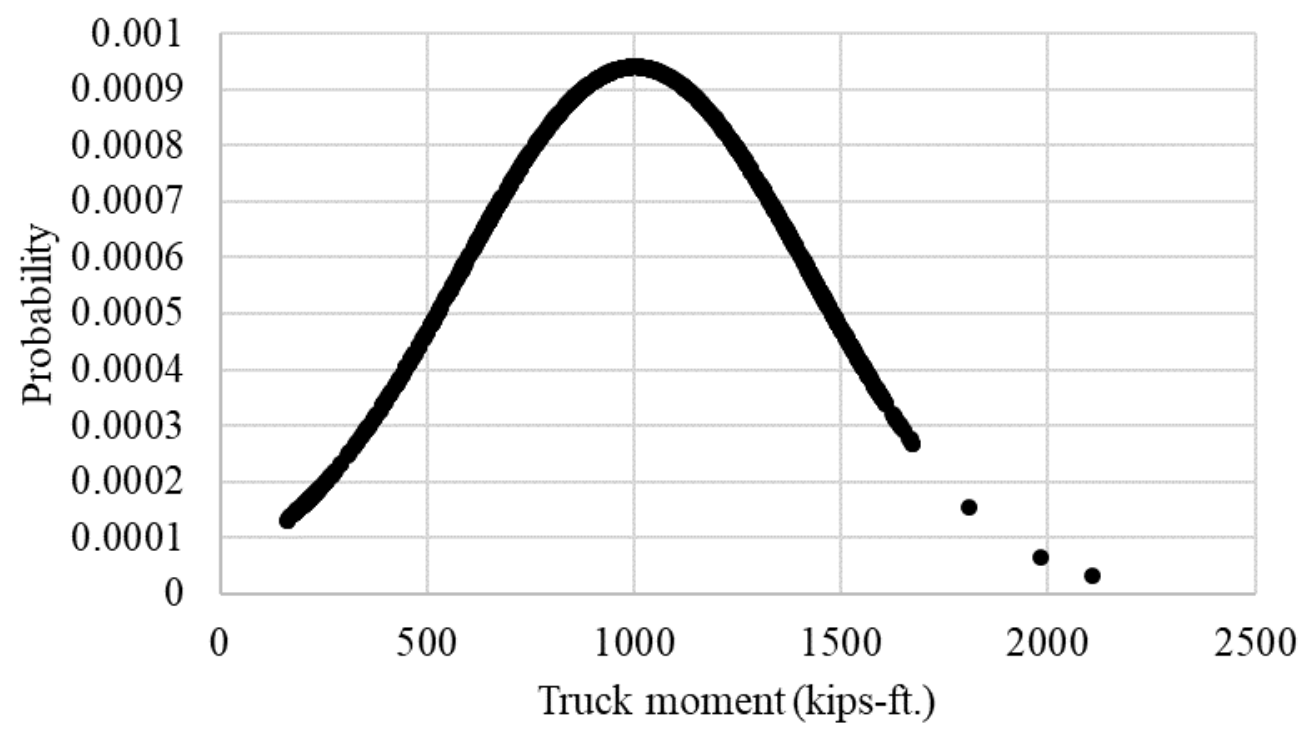

Fig. 3. Probability density function (PDF) for the truck moment 
In this study, since the limit state function is nonlinear, the FORM method is used to linearize failure function. The numerical calculation of the reliability index $\beta$ is an optimization problem with a quadratic objective function and one nonlinear constraint that can be solved using an iterative scheme. By transforming normal distributed random variables $M$ and $l$ to standardized normal distributed random variables (in a new space $u$ ) and assuming two normal variables $U_{l}$ and $U_{2}$, the failure function in the normal u-space was obtained as:

$f(u)=424.6 U_{1}-18 U_{2}-\frac{389}{U_{2}+120}-758.3$

$U_{1}=\frac{M-1002}{424.6}$

$U_{2}=l-120$

$\alpha_{1}=\frac{\partial f_{u}}{\partial f_{1}} \quad \alpha_{2}=\frac{\partial f_{u}}{\partial f_{2}}$

The iteration scheme was converged in 10 iterations and the reliability index $\beta$ was calculated for each trial as shown in Table 2 . The $\alpha$ factors are defined as sensitivity factors giving the relative importance of the individual random variables for the reliability index.

Table 2. Iteration calculation for the non-linear limit state function

\begin{tabular}{ccccccccccc}
\hline Iteration & 1 & 2 & 3 & 4 & 5 & 6 & 7 & 8 & 9 & 10 \\
\hline $\mathrm{U}_{1}$ & 1.000 & 1.790 & 1.790 & 1.790 & 1.790 & 1.790 & 1.790 & 1.790 & 1.790 & 1.790 \\
\hline $\mathrm{U}_{2}$ & 1.000 & -0.076 & -0.076 & -0.076 & -0.076 & -0.076 & -0.076 & -0.076 & -0.076 & -0.076 \\
\hline$\beta$ & 1.414 & 1.792 & 1.792 & 1.792 & 1.792 & 1.792 & 1.792 & 1.792 & 1.792 & 1.792 \\
\hline$\alpha_{1}$ & 424.6 & 424.6 & 424.6 & 424.6 & 424.6 & 424.6 & 424.6 & 424.6 & 424.6 & 424.6 \\
\hline$\alpha_{2}$ & -17.9 & -17.9 & -17.9 & -17.9 & -17.9 & -17.9 & -17.9 & -17.9 & -17.9 & -17.9 \\
\hline $\begin{array}{c}\Sigma \mathrm{i}^{2} \\
(\times 1000)\end{array}$ & 180.6 & 180.6 & 180.6 & 180.6 & 180.6 & 180.6 & 180.6 & 180.6 & 180.6 & 180.6 \\
\hline$\Sigma \alpha_{\mathrm{i}} \mathrm{u}_{\mathrm{i}}$ & 406.6 & 761.5 & 761.5 & 761.5 & 761.5 & 761.5 & 761.5 & 761.5 & 761.5 & 761.5 \\
\hline $\mathrm{f}(\mathrm{u})$ & -354.9 & 0.000 & 0.000 & 0.000 & 0.000 & 0.000 & 0.000 & 0.000 & 0.000 & 0.000 \\
\hline$\lambda$ & 0.004 & 0.004 & 0.004 & 0.004 & 0.004 & 0.004 & 0.004 & 0.004 & 0.004 & 0.004 \\
\hline & & & & & & & & & &
\end{tabular}

\section{Conclusions}

The results showed that the basic random variable $M$, truck moment on the bridge, is dominating with $\alpha$-value equal to 424.6. As a result, after applying the iterative scheme, the reliability index was determined as $\beta=1.79$ for the steel highway bridge. To estimate more accurate results, a comprehensive study with considering more random variables needs to be investigated. 


\section{References}

1. Chandrasekaran, S. (2017). Offshore structural engineering: reliability and risk assessment. CRC Press.

2. Walpole, R. E., Myers, R. H., Myers, S. L., \& Ye, K. (1993). Probability and statistics for engineers and scientists (Vol. 5). New York: Macmillan.

3. Melchers, R. E., \& Beck, A. T. (2018). Structural reliability analysis and prediction. John wiley \& sons.

4. Nowak, A. S., \& Szerszen, M. M. (2003). Calibration of design code for buildings (ACI 318): Part 1Statistical models for resistance. ACI Structural Journal, 100(3), 377-382.

5. Szerszen, M. M., \& Nowak, A. S. (2003). Calibration of design code for buildings (ACI 318): Part 2Reliability analysis and resistance factors. ACI Structural Journal, 100(3), 383-391.

6. Abedin, M., \& Mehrabi, A. B. (2020). Effect of Cross-Frames on Load Distribution of Steel Bridges with Fractured Girder. Infrastructures, 5(4), 32.

7. Rakoczy, A. M., Nowak, A. S., \& Dick, S. (2016). Fatigue reliability model for steel railway bridges. Structure and Infrastructure Engineering, 12(12), 1602-1613.

8. Abedin, M., \& Mehrabi, A. B. (2019). Novel approaches for fracture detection in steel girder bridges. Infrastructures, 4(3), 42.

9. Abedin, M., Farhangdoust, S., \& Mehrabi, A. B. (2019, August). Fracture detection in steel girder bridges using self-powered wireless sensors. In Proceedings of the In Risk-Based Bridge Engineering: Proceedings of the 10th New York City Bridge Conference (p. 216).

10. The American Association of State Highway Transportation Officials (AASHTO) (2012). AASHTO LRFD Bridge Design Specifications, 7th ed.; American Association of State Highway and Transportation Officials: Washington, DC, USA, 2012; ISBN 9781560515234.

11. Choi, S. K., Grandhi, R., \& Canfield, R. A. (2006). Reliability-based structural design. Springer Science \& Business Media.

12. Hayter, A. J. (2012). Probability and statistics for engineers and scientists. Nelson Education. 